\title{
Management plan for UNESCO Shinan Dadohae Biosphere Reserve (SDBR), Republic of Korea: integrative perspective on ecosystem and human resources
}

\author{
Heon-Jong Lee ${ }^{1}$, Kyoung-Man Cho ${ }^{1}$, Sun-Kee Hong ${ }^{2,}$, Jae-Eun Kim², Kyoung-Wan Kim², \\ Kyoung-Ah $\mathrm{Lee}^{2}$ and Kyong-O Moon ${ }^{3}$ \\ ${ }^{1}$ Division of History \& Culture, Mokpo National University, Muan 534-729, Korea \\ ${ }^{2}$ Institution for Marine and Island Cultures, Mokpo National University, Muan 534-729, Korea \\ ${ }^{3}$ Department of International Culture Communication, Krasnoyarsk Pedagogical University, Russia
}

The archipelago in the southwest sea, Korea, was registered as Shinan Dadohae Biosphere Reserve by United Nations Educational, Scientific and Cultural Organization Man and the Biosphere (UNESCO MAB) on May 26, 2009. This study was conducted to determine a method of reconciling natural and anthropogenic processes and to enable sustainable development in the vicinity of the Shinan Dadohae Biosphere Reserve (SDBR). To accomplish this, the characteristics of SDBR with respect to biodiversity and cultural diversity were evaluated. In addition, a management plan regarding the wise use of the SDBR was developed while focusing on four parts: cultural support to induce motivation for native conservation and development; development and specification of fisheries and cultivation based on local community systems; restructuring of marine food products and resource transporting systems; activation and discovery of indigenous knowledge to enable networking between local residents, academia and the UNESCO-international society.

Keywords: biodiversity, island culture, Shinan Dadohae Biosphere Reserve, sun-dried salt, sustainable development, tidal flat, UNESCO

\section{INTRODUCTION}

Shinan Dadohae Biosphere Reserve (SDBR) consists of 1,000 islands bordering the southwest coast of Korea in East Asia. Dadohae National Park located in Shinan County includes most of the SDBR. The SDBR will contribute to the conservation of the natural environment in this marine area and to the sustainable development of human life. SDBR shows ecological, topological and cultural diversity that includes both marine spaces and the island forest ecosystem (Koh 2001). Surrounding the islands of the SDBR are tidal flats, which are complicated tidal waterways that differ significantly between high and low tide and contribute to unique geographical and biological diversity (Korea Ocean Research and Development Institute 2001, 2002). In addition, individuals living in the SDBR have established a unique island culture based on the unique geographical and biological characteristics of the region (Cho 1995). SDBR encompasses unique ecological entities that sustain the continuum of ocean, large tidal-flats and thousand of islands and forests (Table 1).

\section{THE CHARACTERISTICS OF SDBR AND ZONING}

Received 20 January 2009, Accepted 6 April 2010

"Corresponding Author

E-mail: landhong@yahoo.co.kr

Tel: +82-61-450-6272 (cc) This is an Open Access article distributed under the terms of the Creative Commons Attribution Non-Commercial License (http://creativecommons.org/licenses/by-nc/3.0/) which permits unrestricted non-commercial use, distribution, and reproduction in any medium, provided the original work is properly cited. 
Table 1. Land use pattern in Shinan Dadohae Biosphere Reserve

\begin{tabular}{lcccr}
\hline & Heuksando (ha) & Hongdo (ha) & Bigeumdo \& Dochodo (ha) & Jeungdo (ha) \\
\hline Inhabited area & 71.91 & 13.09 & 319.12 & 61.48 \\
Agricultural area & 187.39 & - & 3631.53 & 539.45 \\
Forest area & 2132.05 & 652.04 & 9248.79 & 354.78 \\
Grassland area & 214.19 & - & 4233.20 & 33.04 \\
Wetland area & 2.34 & - & 3910.86 & 1790.92 \\
Bare land area & 54.42 & 1125.04 & 2260.23 & 51.00 \\
Water surface & 3660.27 & 17.94 & 37784.28 & 1319.86 \\
Others & 48.03 & 1808.10 & 2007.42 & 24.85 \\
Total & 6370.60 & & 63395.43 & 4175.38 \\
\hline
\end{tabular}

SDBR has a total area of 75,749 ha that is described as follows. The core area is 3,439 ha $(4.5 \%$ of the entire area), the buffer zone is 26,038 ha $(34.4 \%$ of the total area), and the transition area covers 46,272 ha $(61.1 \%$ of the overall area). The core area includes three islands designated as Dadohae National Park and four natural monuments.
This area is a mixed ecosystem composed of a terrestrial ecosystem, a maritime ecosystem and a tidal-flat ecosystem, all of which are interconnected (Koh 1997). Various animals and plants have adapted to the unique topographical regions in the core area. Dozens of warmtemperate evergreen broad-leaved trees, conifers and

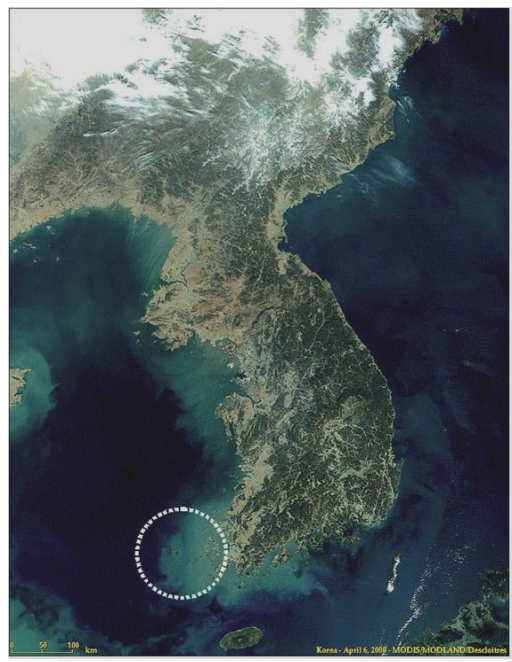

\section{Hongdo}

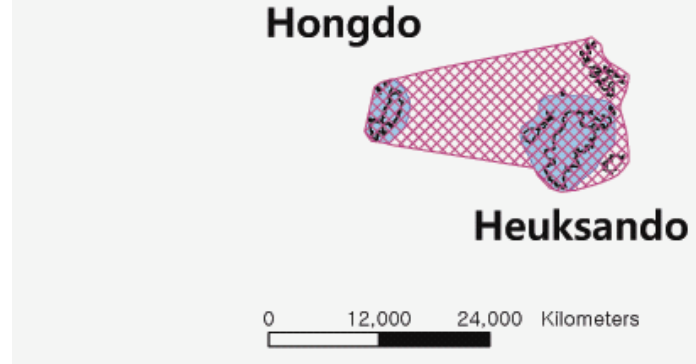

Heuksando

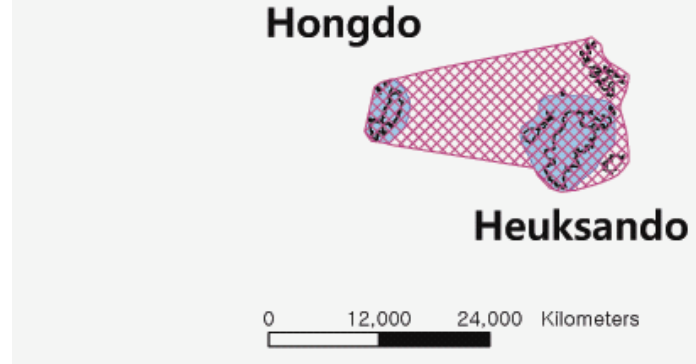

Legend

Dadohaehaesang National Park

Biosphere Reserve area

שTidal Flat Provincial Park
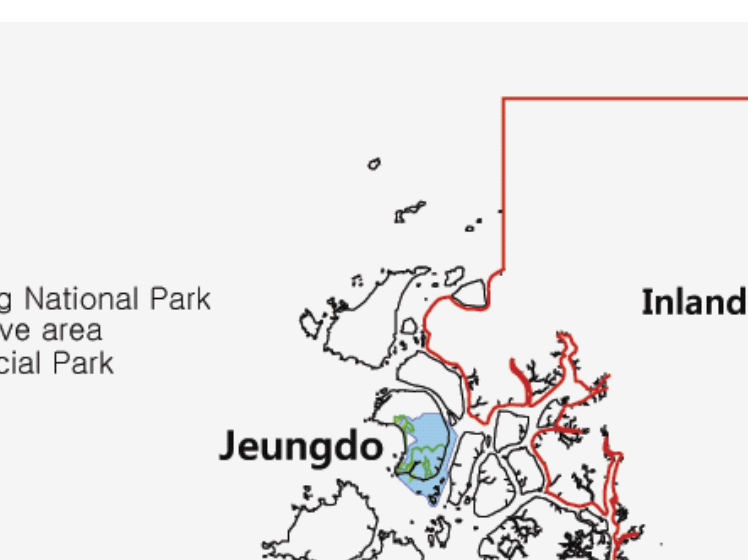

Bigeumdo
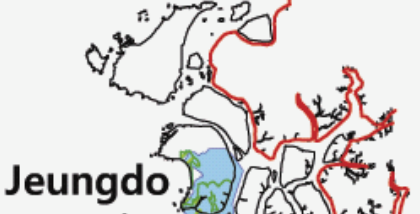

Inland

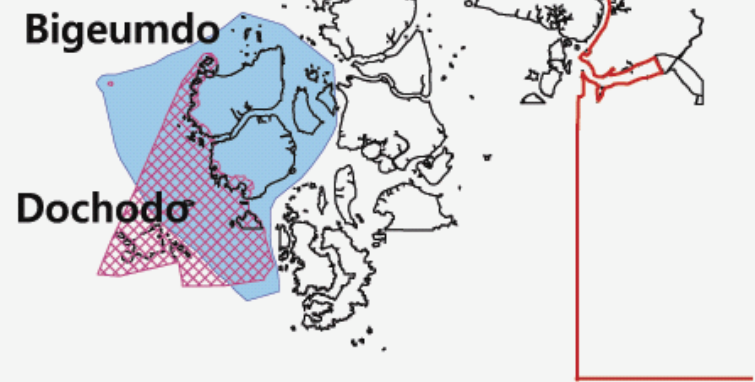

Fig. 1. Location and zonation map of Shinan Dadohae Biosphere Reserve 
rare plants designated as natural monuments grow naturally in geographically isolated areas of the terrestrial regions of the core area. The region is subject to an oceanic climate; thus, warm and moist weather support a temperate broad-leaved forest ecosystem and an evergreen broad-leaved forest ecosystem that exist within the region. As a result, this area is a very important eco-region academically that plays a significant role in the valuable coast and island ecological axis of the Korean National Ecological Network (Fig. 1).

Various marine organisms can be found in the tidal flat of SDBR including benthic macro-invertebrates and macrophytes (Koh and Shin 1988, Lim et al. 1997). Highly diverse species of salt marsh and sand dune plants, tidal flat animals and sand dune insects contribute to an abundant food chain and increased stability of an intertidal ecosystem. The tidal flat supports 13 species of birds identified as natural treasures including the Black-faced Spoonbill (Platalea minor), Oystercatcher (Haematopus ostralegus), Golden Eagle (Aquila chrysaetos), Osprey (Pandion haliaetus), and Oriental Honey Buzzard (Pernis ptilorhynchus). In addition, 337 species of rare migratory birds as well as endangered birds including the Golden Eagle (A. chrysaetos), (P. haliaetus), and Oriental Honey Buzzard (P. ptilorhynchus) live in or pass through this tidal flat (Fig. 2).

The landscape of this area exists as an ecological ecotone that gradually connects the sea, tidal-flats, coastal beaches, sand dunes and vegetation in an environmental gradient. The variety of organisms in the area illustrates the results of ecological adaptation to a multi-ecosystem spectrum and its continuity, which leads to a higher conservation value of the marine and landscape diversity (Hong et al. 2010).

To create sustainable development, a zone of 48,668 ha will be designated based on the landscape and biological diversity. Within this zone, economic development can be realized through creation of a cultural and economic system that will be reconciled with the continuum of various marine and island ecosystems. In this area, environmentally sound technologies based on previous, adaptive use of the ocean, tidal-flat and island ecosystems have al-

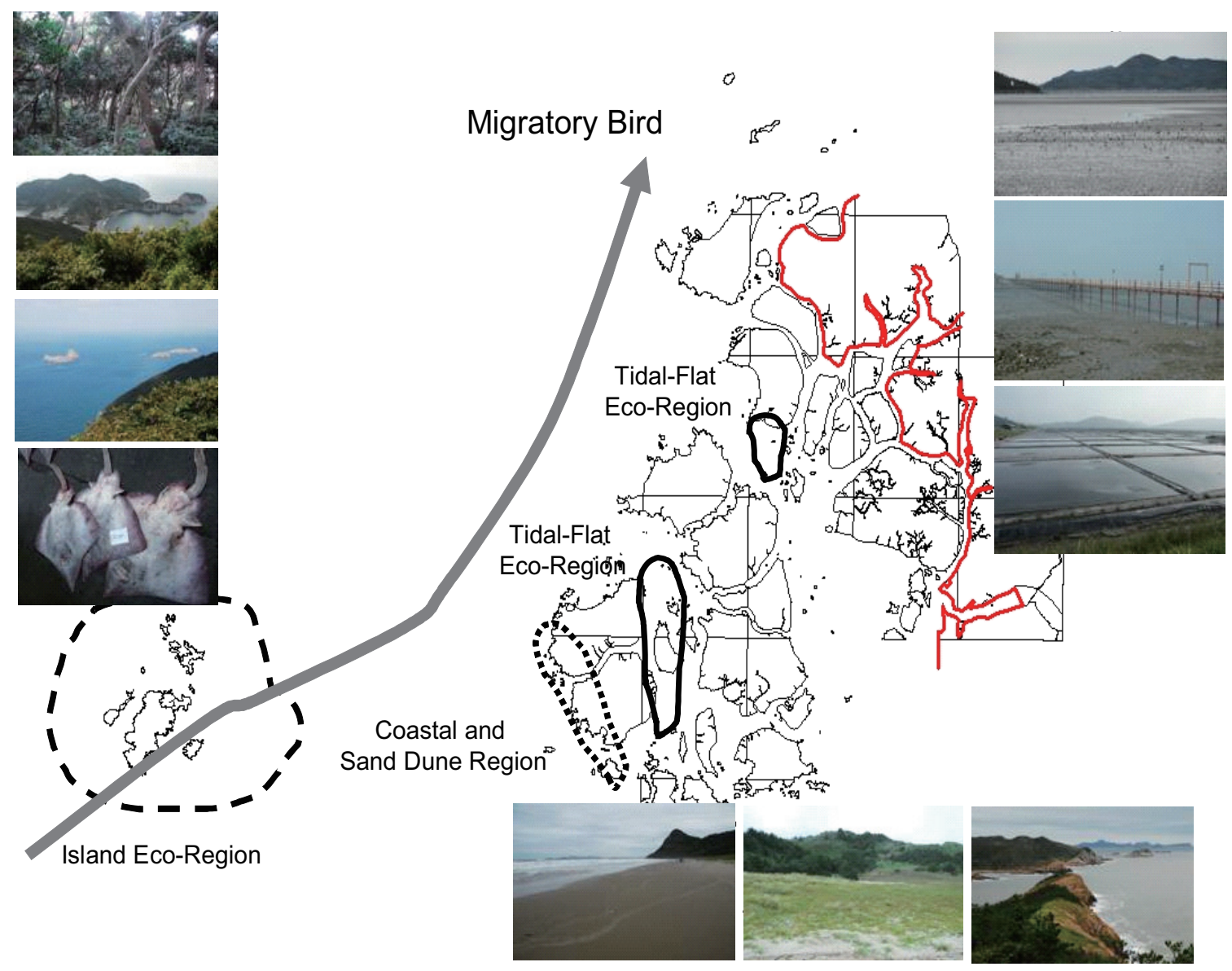

Fig. 2. Representative migratory birds and their main route in Shinan Dadohae Biosphere Reserve 
ready been developed. Therefore, these technologies can be revitalized to create sustainable new technologies and social organizations. Indeed, there is already demand for such technologies in the local societies, governmental offices and academic facilities. SDBR will also foster development of the local industry of natural products and ecotourism, which should satisfy the current aesthetic sensibilities of modern nature enthusiasts.

\section{ECOLOGICAL AND SOCIO-ECONOMIC CHARAC- TERISTICS OF THE SDBR}

\section{Tidal flat nutrient cycling}

The fishermen in the SDBR have their own sense of values to estimate the quality of the fish based on the nutrients and strong influence that the tidal flat has on the taste of the fish, shellfish and seaweed that inhabit the tidal flats, sea water and rock crevices in the region. As a result, the harvest of this area is different from that of other areas. Salt is also abundant in the tidal flats. Indeed, salt made by the sun or using fire is rich in minerals and was a symbol of wealth in the past (Ministry of Oceanic and Marine Products 1999a, 1999b). Even today, the salt from this region is enjoyed and nationally recognized for its quality and natural benefits (Table 2). This recognition has gradually begun to reach other countries; therefore, using the connection between the tidal flats and salt through local industry is a critical method of maximizing the value of natural products and revitalizing the local economy. Moreover, the local food culture of this region has traditionally used salt to ferment fish, which has now has become a national tradition (Ministry of Oceanic and Marine Products 2002). In light of this specific food culture, the fish and salt become related industries developed as the principle axis of the local economy (Table 3).

\section{Local environmental and economic values and opportunity for sustainable development}

The harvesting of seaweed in the tidal flats and the shores has traditionally been controlled by a village organization known as 'Joobi' (Cho 1995). The main function of Joobi is to guarantee equal opportunities with respect to access to resources and to enhance co-management, which results in preventing over-harvesting. Currently, modern village fishing cooperatives (Eochongye) have similar responsibilities and in some places, the activities of cooperative are operating on the principle of the traditional Joobi. However, the function of self-regulation or conservation of these cooperatives has been weakened, distorted or even disappeared altogether in some cases. Therefore, establishment of the SDBR is quite meaning-

Table 2. The area of salt pan in Shinan Dadohae Biosphere Reserve

\begin{tabular}{lccccc}
\hline & & Area (ha) & \multicolumn{2}{c}{ No. of private enterprises } \\
\cline { 2 - 6 } & Permitted & Operation & Closing & Permitted & Production \\
\hline Entire nation & 4,737 & 3,926 & 811 & 1,275 & 1,119 \\
Jeonnam province & 3,330 & 2,977 & 353 & 284 & 925 \\
Shinan county & 2,435 & 2,151 & 35.0 & 72.6 & 818 \\
Comparison with nation (\%) & 51.4 & 54.7 & 80.4 & 81.5 & 81.8 \\
Comparison with Jeonnam (\%) & 73.1 & 72.2 & & 8.1 \\
\hline
\end{tabular}

Table 3. The output of sun-dried salt

\begin{tabular}{|c|c|c|c|c|c|c|}
\hline & \multicolumn{5}{|c|}{ Output (ton) } & \multirow{2}{*}{ Total stock } \\
\hline & 2003 & 2004 & 2005 & 2006 & 2007 & \\
\hline Entire nation & 156,000 & 340,000 & 334,000 & 285,568 & 296,108 & 102,693 \\
\hline Jeonnam province & 138,000 & 291,000 & 288,241 & 235,440 & 258,353 & 91,263 \\
\hline Shinan county & 125,426 & 237,948 & 210,933 & 174,040 & 192,853 & 74,283 \\
\hline Comparison with nation (\%) & 80.0 & 70.0 & 63.1 & 60.9 & 65.1 & 72.3 \\
\hline Comparison with Jeonnam (\%) & 90.8 & 81.7 & 89.6 & 73.9 & 74.6 & 81.3 \\
\hline
\end{tabular}


ful in that it will restore traditional conservation functions in conjunction with modern organizational activities. Indeed, the SDBR will create effective solutions that stabilize the income of local individuals while sustaining resources.

Food culture and the landscape are distinctive and prospective conditions for ecotourism. The Shinan Dadohae Islands are a unique group of approximately 1,000 islands surrounded by tidal-flats, oceans with intricate waterways and fauna habitats, precious temperate evergreen forests, indigenous sea shore and inland plant vegetation, all of which contribute nutrition to the shallow ocean areas in the region.

The SDBR is famous for local fish stocks, fermented food resources and cuisine, particularly raw or semidried fish (Table 4). Applying these traditions combined with the SDBR's target of sustainable use could result in slow food and slow lifestyles, which is already in practice in the Shinan Islands. Accordingly, the SDBR has the potential for further expansion to construct a slow food system nationwide.

Agricultural products, medicinal plants, flowers and forest products can be used as unique environmental products in local primary industry. Spinach thrives in the region due to the ample sunshine and soil conditions. In addition, root, bulb, and stem plants are isolated from any viruses present on the mainland. Moreover, the bark of evergreen broad-leaved trees and medicinal plants can develop in these areas. These plants are well adapted to the regional environment; however, they must be reorganized into a system that enables environmentally friendly production and gathering. Finally, the value of local tourist attractions and local commodities would be increased by the direct connection with slow food or the symbolic association of body-region-food and bodyregion-medicinal plants.

To date, modern technical information systems operated by specialist institutions or executive agencies, gov- ernmental agencies or research organizations have been quite effective at fostering sustainable fisheries and other local production. Local leaders also have an awareness and considerable experience concerning resource issues. However, a suitable integrative system to vitalize this organizational social capital and the local cultural experiences is needed to regulate ego-centered economic activities that result in environmental degradation to enhance the economy (Kiss 2004). In addition, existing fishery organizations should be developed into unique organizations that are capable of utilizing Korea's powerful producer-consumer liaisons. In Korea, urban consumer and rural producer liaisons are widely distributed (Ministry of Environment 2005), and these relationships are based on intimate partnerships or co-ops. Cultural sentiments of Korean human relationships and credibility operate here (Ministry of Oceanic and Marine Products 2002). Traditional or modern cultural activities, autonomous decision making with respect to social organizing and management of credibility all work together well in these partnerships. As a result, the SDBR can easily establish outside partnerships to enable an open system of economic, social and cultural liaisons. Currently, this internal SDBR and outer open system is being developed with Shinan County, local residents, nearby universities and NGOs. This system will be a powerful cultural path that enables the SDBR to realize its ideals of conservation and development. Based on these possibilities, the following enhanced programs for conservation and sustainable development are being developed.

First, enhancement of the interdependence between nature and human beings is envisioned. To accomplish this, a socially cooperative communication system will be designed. Second, enhancement of the natural value will integrate the elaborate ecosystems that exist from the ocean to the forest. The natural value will be empowered by indigenous knowledge, cultural behavior and customs of local people. Third, the enhancement of ecotourism

Table 4. The number of farming \& fishing households and the people

\begin{tabular}{lcccccccc}
\hline \multirow{2}{*}{ Name of myeon } & \multicolumn{2}{c}{ Total } & \multicolumn{2}{c}{ Agriculture } & \multicolumn{2}{c}{ Fishery } & \multicolumn{2}{c}{ Side job } \\
\cline { 2 - 8 } & Household & People & Household & People & Household & People & Household & People \\
\hline Total of Sinan county & 6,092 & 12,935 & 3,120 & 6,235 & 1,699 & 3,810 & 404 & 952 \\
Heuksan-myeon & 2,258 & 4,777 & 369 & 760 & 1,491 & 3,223 & 147 & 279 \\
Bigeum-myeom & 1,382 & 2,773 & 1,018 & 2,2047 & 28 & 65 & 18 & 52 \\
Docho-myeon & 1,483 & 3,193 & 1,129 & 2,246 & 63 & 147 & 74 & 254 \\
Jeungdo-myeon & 969 & 2,192 & 604 & 1,182 & 117 & 378 & 165 \\
\hline
\end{tabular}


Table 5. The number of tourists visiting Shinan Dadohae Biosphere Reserve in 2006

\begin{tabular}{lccc}
\hline Area & Korean & Foreigners & Total \\
\hline Hongdo & 147,713 & 120 & 147,833 \\
Heuksando & 174,232 & 299 & 174,531 \\
Bigeumdo & 47,826 & 26 & 47,852 \\
Dochodo & 48,364 & 0 & 48,364 \\
Jeungdo & 71,950 & 27 & 71,977 \\
Total & 490,085 & 472 & 490,557 \\
\hline
\end{tabular}

Table 6. Tourism demand

\begin{tabular}{lcccc}
\hline & 2001 & 2004 & 2008 & 2013 (estimated) \\
\hline Jeonnam province (A) & 46,689 & 49,219 & 60,848 & 75,384 \\
Sinan county (B) & 478 & 1,477 & 4,867 & 7,538 \\
B/A (\%) & 1.02 & 3.0 & 8.0 & 10.0 \\
\hline
\end{tabular}

and cultural tourism will integrate synchronic diverse ecosystems and cultural areas, as well as the diachronic experiences of ocean and island lives. In addition, the Shinan Islands and the ocean contain remarkable relics from a shipwreck that occurred in the $14^{\text {th }}$ century, which highlights the historical role the region played in shipping among Korea, China and Japan. Finally, enhancement of the local revenue would integrate the ecological and cultural path of production, tourism and property of intelligence based on local knowledge and sensibility, all of which would be impossible to operate without the experience and labor of local individuals and labor.

The SDBR plays an important role in that it protects the local ecosystem from invasion by tourist facilities that do not match the local environment and culture, extract local resources and degrade the ecosystem (Table 5). The SDBR will also create a market for ecological and cultural tourism and will serve as the first model of authentic marine eco-tourism in Korea (Table 6). This developmental strategy will match the growing needs of contemporary Korean citizens for nature, culture and identity, generating reciprocal revenues.

\section{Development and utilization of alternative energy}

Solar energy, wind energy, tidal energy, and biogas are very important resources in the face of climate change. Not only has alternative energy been touted as a solution to environmental problems, in light of rising oil prices alternative energy also has the potential to provide economic relief to consumers. As a result, this situation has led to increasing economic value of alternative energy forms. Because it has been difficult to supply electric- ity to the isolated islands in the SDBR, the islands must find a source of electricity. As a result, Jeungdo Island has already introduced a solar power generator that takes advantage of the island's abundant sunshine. The SDBR provides an opportunity to expand upon the islands' existing alternative energy sources.

The terrestrial area of SDBR only consists of islands. The main industry in the region is agriculture and fisheries, and the main natural resources are the environment, the landscape, and agricultural and marine products. Sustainable development in the SDBR could be based on self-regulation of the community (fishing village cooperatives and common fishing grounds) formed by the local residents' spontaneous participation. Sustainable development could be achieved by the promotion of hand fishing in the buffer zone, which is the traditional method of fishing, as well as by the use of fish farms, salt production, agriculture, and tourism in the transition area.

The designation of a UNESCO Biosphere Reserve is designed to provide opportunities that utilize regional traditions, while changing such traditions into a system of ecological resource management and human economic development that can adapt to future changes (UNESCO's Man and the Biosphere 2008). This enables utilization of cultural landscape systems that have already been adapted to and to figure it out to the cultural ecology of modern society to be more complicated (Hong et al. 2007). Simultaneously, designation of UNESCO Biosphere Reserves enables formation of appropriate technology and the appropriate socio-culture without exceeding the ecological capacity and providing negative feedback. It is possible to establish a long-term future plan for sustainable ecology, culture, and economy in the 
Dadohae Region (Hong et al. 2010). This is especially true for the tidal flat in the transition area, which functions to conserve natural resources and purify pollution created by humans. Islands and the sea surround most of the tidal flat (Ihm et al. 1998, Kim et al. 2007); however, considering the local industry, there is little possibility of damaging the regional ecosystem. In case of saltpans, it includes the restoration power of the tidal flat. The saltpan permeates into the tidal flat via the nutrition of the natural ecosystem, thereby becoming a source of nutrients to shallow-sea fish. These tidal flats and saltpans are synonymous with organism diversity. Individuals in the area make a living by gathering marine products. Taken together, these characteristics provide conditions that make a sustainable economy possible.

SDBR is an Eco-region in which a broad-leaved forest ecosystem and evergreen forest ecosystem coexist in a warm and humid oceanic climate zone. Dadohae National Park is included in the important coastal axis of national ecological networks in Korea. The tidal flats and salt flats in the buffer zone and transition area are an historic space in which the activities and identity of local people have been passed down through the generations as they learned to adapt to the natural environment and developed their own indigenous knowledge. Therefore, the multi-layered beauty of the natural environment bears the historical traits of human adaptation to the environment along with its diverse biological resources. As a result, this region should be regarded as an important cultural-ecological resource for promoting local sustainability.

The flora and fauna, culture and ecology of islands and tidal flats are not only important in terms of attracting visitors, but are also useful academic resources (Gössling 1999). The distribution of natural resources from the terrestrial ecosystem to the sea via the tidal flat is valuable for eco-tourism and the local ecological economy. Dadohae National Park contains many sandy beaches and tidal flats, and the vegetation and salt marsh plants provide an important resource and habitat for migratory birds.

The fishing industry in Korea has been developed to satisfy the necessary level of environmental and ecological protection for specific local ecosystems. Designating Dadohae National Park as a UNESCO Biosphere Reserve will further establish its potential for fostering economic and human development and creating an ecologically sustainable ecosystem. In the long term, SDBR will fulfill an outstanding historical and cultural role as a global model for conservation and development to promote the concept of a sustainable ecosystem, culture, and economy.

\section{MANAGEMENT PLAN - ECOSYSTEM APPROACH}

\author{
Motivation for native conservation and develop- \\ ment
}

Human beings are part of the natural ecosystem, having long adapted to the natural environment in order to produce tools and food. Indeed, this is the definition of culture. SDBR contains many ecological-cultural elements that demonstrate the linkage between humans and nature, and show the possibility for a cultural plan that embodies the future of environmental conservation and sustainable development. In SDBR, the sea has long served as a geographically significant shipping route and maritime cultural corridor linking the continent and islands of East Asia. Beyond East Asia, the cultural routes for export and cooperation expanded from the Korean peninsula to the Indo-China Sea. As a result, long-term historical accumulations of cultural interchange are part of the valuable identity and serve as motivation for developing marine culture in Korea.

\section{Development and specification of fisheries and cultivation based on local community systems}

People adapt to their local environments based on nature-based indigenous knowledge and empirical knowledge gained over time. 'Pasi' is a traditional fish market that opens when there are large catches of fish. However, due to the modernization of the fishing industry, the culture and tradition of Pasi has disappeared. The collapse of traditional culture is related to maritime environmental conditions, and over-fishing and oceanic pollution are major causes of degradation of the fishing industry and the quality of the marine ecosystem.

Despite this exhaustion of marine resources and degradation of the ecosystem, the ability of people to sustain the balance of marine ecosystems has persisted. For example, fishing village cooperatives and village common fishery grounds are social devices created to sustain the balance of the ecosystem according to the traditional rule of self-regulation in the community village. These traditional methods for preserving tidal flats have been transmitted from generation to generation. Although tidal flats are state property, fishing village cooperatives regulate the gathering time, place and productivity. The range of the harvesting area and productivity of the village common fishery ground is decided by the village unit and local families based on geomorphologic boundaries. Such fishing village cooperatives manage the village common 
fishery grounds directly. People living in the area that now forms Dadohae National Park planted the trees and built the stone walls (known as 'woosil') that protect the village from strong sea winds. Although the 'woosil' functions as a windbreak in the modern sense of the term, in ancient times, it had an added spiritual meaning.

\section{Restructuring of marine food product and re- source transporting system}

Salt produced from the tidal flats in Dadohae National Park is a product of the ecosystem; however, it is produced by humans. By branding "sun-dried salt" produced according to indigenous methods, salt can contribute to sustainable economic development. Food resources from the sea and tidal flat (fish, shellfish, algae, salt, etc.) provide nutrients (proteins, vitamins, minerals, etc.) essential to sustain human life. The economic system for obtaining, distributing, and consuming these food resources influences the future possibilities for environmentally sound and ecological development. The characteristics of the natural landscape and geomorphology, including islands, tidal flats, and fish biodiversity, in Dadohae National Park are fundamental to the development of maritime food resources (Table 7). These resources, which include tangle weed, abalone, sea cucumber, laver, and brown seaweed, are gathered according to appropriate traditional methods and symbolize the cleanliness of the sea water.

To strengthen the environmentally friendly characteristics and locality of maritime food products, programs to strengthen local technologies in the fishing industry, environmental industry and cultivation techniques should be developed. Concerning distribution, consumers can be made aware of the need for environmental conservation and environmentally friendly labor practices at the time of purchase. Moreover, consumers can gain confidence in local food systems and ensure their economical value through the cooperative system among fishermen, distributors, and consumers. Considering that there is an increasing desire for widened socio-cultural activity in Korean society, such a cooperative system would help support these socio-cultural activities while ensuring economic activity.

\section{Activation and discovery of indigenous knowl- edge}

Local universities and institutes have examined the characteristics of island and tidal flat ecosystems and evaluated sustainable development using those ecological resources. Jangdo wetland in the core zone of Heuksando, which was designated as a Wetland Protection Area in 2004, was renamed as the Ramsar Wetland Site in 2005. Tidal flats in the Jeungdo area were designated a Provincial Tidal Flat Park in June of 2008. To designate the tidal flat ecosystems in Bigeum-myeon and Dochomyeon in Shinan-gun as a Wetland Protection Area, the local government is attempting to establish an Island Ecosystem Conservation Act. In addition, the national government is trying to find a method enabling integrated environmental management of coastal and island areas, including uninhabited islands.

\section{ACKNOWLEDGMENTS}

We thank the many researchers who provided valuable data enabling designation of the SDBR. We also thank Jeonnam Province and Shinan County, Republic of Korea. This work was supported by the National Research Foundation of Korea Grant funded by the Korean Government (NRF-2009-361-A00007).

\section{LITERATURE CITED}

Cho KM. 1995. Island ecosystem and island culture: a review of the studies on the island cultures in the southwestern

Table 7. Production incomes by marine products

\begin{tabular}{|c|c|c|c|c|c|c|c|c|c|c|c|c|}
\hline & \multicolumn{2}{|c|}{2001} & \multicolumn{2}{|c|}{2002} & \multicolumn{2}{|c|}{2003} & \multicolumn{2}{|c|}{2004} & \multicolumn{2}{|c|}{2005} & \multicolumn{2}{|c|}{2006} \\
\hline & Yield & Income & Yield & Income & Yield & Income & Yield & Income & Yield & Income & Yield & Income \\
\hline Total & 91,465 & 152,078 & 98,480 & 163,899 & 93,335 & 126,530 & 67,814 & 147,525 & 92,331 & 220,004 & 86,952 & 186,178 \\
\hline Fish & 14,540 & 74,721 & 17,540 & 78,678 & 30,380 & 39,730 & 11,665 & 56,900 & 19,407 & 127,301 & 13,815 & 78,500 \\
\hline Crustacea & 10,780 & 17,444 & 12,340 & 21,431 & 13,000 & 42,300 & 15,000 & 53,210 & 14,104 & 40,220 & 13,832 & 34,530 \\
\hline Mollusk & 1,509 & 1,439 & 1,800 & 1,789 & 1,000 & 500 & 1,582 & 4,760 & 1,582 & 4,760 & 2,211 & 9,695 \\
\hline Seaweed & 60,110 & 58,292 & 62,000 & 59,780 & 45,048 & 35,720 & 35,655 & 24,870 & 52,757 & 33,769 & 54,922 & 35,583 \\
\hline Others & 4,526 & 182 & 4,800 & 2,221 & 3,907 & 8,280 & 3,912 & 7,785 & 4,481 & 13,954 & 2,172 & 27,870 \\
\hline
\end{tabular}


part of Korea. Moden Soc Sci Res 6: 193-219.

Gössling S. 1999. Ecotourism: a means to safeguard biodiversity and ecosystem functions? Ecol Econ 29: 303-320.

Hong SK, Nakagoshi N, Fu B, Morimoto Y. 2007. Landscape Ecological Applications in Man-Influenced Areas: Linking Man and Nature Systems. Springer-Verlag, Dordrecht.

Hong SK, Koh CH, Harris RR, Kim JE, Lee JS, Ihm BS. 2010. Land use in Korean tidal wetlands: impacts and management strategies. Environ Manage 45: 1014-26.

Ihm BS, Kang JH, Lee KC. 1998. Studies on the Structure and Function of Coastal Wetland Ecosystem to Conserve Coastal Area. Mokpo National University, Muan.

Kim JM, Kim JM, Lee SM. 2007. Development of modules for the restoration of tidal-flat. J Kor Soc Mar Environ Eng 10 Suppl: 127-130.

Kiss A. 2004. Is community-based ecotourism a good use of biodiversity conservation funds? Trends Ecol Evol 19: 232-237.

Koh CH. 1997. Korean megatidal environments and tidal power projects: Korean tidal flats-biology, ecology and land uses by reclamation and other feasibilities. La Houille Banche 3: 66-78.

Koh CH. 2001. Geomorphology and dyking of the Korean tidal flat. In: The Korean Tidal Flat: Environment, Biology, and Human (Koh CH, ed). Seoul National University Press, Seoul, pp 76-85.

Koh CH, Shin HC. 1988. Environmental characteristics and distribution of macrobenthos in a mud flat of the west coast of Korea (Yellow Sea). Neth J Sea Res 22: 279-290.
Korea Ocean Research and Development Institute. 2001. Studies on Inventories and a Sustainable Use of Tidal Flats in Korea, BSPM 118-00-1370-3. Ministry of Maritime Affairs and Fisheries, Busan.

Korea Ocean Research and Development Institute. 2002. Studies on Inventories and a Sustainable Use of Tidal Flats in Korea, BSPM 16100-1465-3. Ministry of Maritime Affairs and Fisheries, Busan.

Lim HS, Park KY, Ihm BS, Lee JS, Chu SD. 1997. Macrozoobenthic community on the mud-tidal flat around Mokpo coastal area, Korea. Korean J Ecol 20: 355-365.

Ministry of Environment. 2005. A Study on Natural Environment Protection Plan of Islands and Costal Area. Korean Environmental Policy Evaluation Research Center, Gwachon.

Ministry of Oceanic and Marine Products. 1999a. Tidal-flat Ecosystem Research and the Study on Sustainable Using Plan I, BSPM 99035-00-1228-3. Ministry of Maritime Affairs and Fisheries, Busan.

Ministry of Oceanic and Marine Products. 1999b. Tidal-flat Ecosystem Research and the Study on Sustainable Using Plan IV, BSPM 16100-1465-3. Ministry of Maritime Affairs and Fisheries, Busan.

Ministry of Oceanic and Marine Products. 2002. Korean Maritime Culture 2, the West Sea Area, Vol. 1. Institute of Islands Culture, Mokpo National University, Muan.

UNESCO's Man and the Biosphere. 2008. Madrid Action Plan (MAP) for Biosphere Reserves (2008-2013). UNESCO MAB, Paris. 